\title{
Plantão psicológico a partir de uma escuta psicanalítica
}

\section{Psychological emergency attendance through a psychoanalytical listening}

\author{
Ana Claudia Broza Daher ${ }^{1}$, Maria Lúcia Mantovanelli Ortolan², Maíra Bonafé Sei ${ }^{3}$, \\ Kawane Chudis Victrio ${ }^{4}$
}

\section{Resumo}

O plantão psicológico se configura como uma intervenção psicológica implementada no Brasil a partir de um referencial humanista, abordagem teórica ainda predominante na literatura sobre o tema. Organizase como um tipo de intervenção clínica que oferta um atendimento pontual, realizado o mais próximo possível da necessidade do indivíduo, por meio do qual pode-se fazer, além de um acolhimento, também um esclarecimento acerca da demanda desta pessoa. Tendo em vista a importância e pertinência desta prática, buscou-se ofertá-la em 2015 em um serviço-escola de Psicologia de uma universidade pública. Diante deste cenário, almejou-se discutir a prática do plantão psicológico, realizada por meio de um projeto de extensão, enfatizando a escuta psicanalítica empreendida neste contexto. Considera-se que, no plantão psicológico, o plantonista acaba por se deparar com a escuta do inesperado, do inconsciente que insiste para que seja ouvido. Espera-se, assim, que, ao mesmo tempo em que é escutado, o próprio sujeito que fala se ouça e que esta escuta possa, de alguma forma, contribuir para que ele se reposicione ou ressignifique o motivo que o fez procurar o atendimento.

Palavras-chave: Plantão psicológico. Psicanálise. Serviço-escola de Psicologia.

\begin{abstract}
The psychological emergency attendance configures itself as a psychological intervention implemented in Brazil from a humanist framework, theoretical approach that still prevails in the literature on the subject. It organizes itself like a kind of clinical intervention that offers a punctual service, accomplished the closest possible to the individual's necessity, whereby it's possible to make, besides a reception, also an enlightenment about the person's demand. Considering the importance and relevance of this practice, it was sought to offer it in 2015 in a psychology school service of a public university. In this scenario, the objective of this paper was to discuss the practice of psychological emergency attendance held through an extension project, emphasizing the psychoanalytical listening undertaken in this context. It is considered that, in psychological emergency attendance, the psychologist eventually is faced with the listening of the unexpected, the unconscious that insists to be heard. It is expected, therefore, that at the same time it is heard, the individual who speaks can listen to himself and that this listening can somehow contribute to his repositioning or re-signifying the reason that made him seek care.
\end{abstract}

Keywords: Psychological emergency attendance. Psychoanalysis. Psychological university clinic.

\footnotetext{
Psicóloga. Especialista em Avaliação Psicológica e em Psicologia Clínica e da Saúde.

2 Psicóloga. Residente em Saúde da Família pela Universidade Estadual de Londrina. E-mail: ortolan78@gmail.com

3 Psicóloga. Doutorado e Pós-Doutorado em Psicologia Clínica pelo IP-USP. Professora Adjunta do Departamento de Psicologia e Psicanálise da Universidade Estadual de Londrina

4 Psicóloga pela Universidade Estadual de Londrina
} 


\section{Plantão Psicológico: Histórico e Panorama Geral}

O serviço de Plantão Psicológico foi inaugurado no Brasil no início dos anos 1960 por Rachel Rosemberg. Tal profissional implantou este tipo de atendimento no Serviço de Aconselhamento Psicológico (SAP) do Instituto de Psicologia da USP (IPUSP), tendo a Abordagem Centrada na Pessoa de Carl Rogers como referencial, no intuito de oferecer um atendimento diferenciado à clientela que procurava o serviço, constituindo-se como uma alternativa às longas filas de espera (FUJISAKA et $a l, 2013$; ROCHA, 2011).

Apresenta-se como uma modalidade de atendimento de tipo emergencial, que almeja acolher o sujeito no momento mais próximo de sua necessidade, auxiliando-o a manejar seus recursos e limites (BRESCHIGLIARI; JAFELICE, 2015). Trata-se, assim, de uma intervenção realizada sem agendamento prévio, por meio do acolhimento dado por um profissional que se posiciona à espera do interessado em um local e horário previamente determinados. Pode ser também intitulado como pronto atendimento psicológico, denominação que busca afastar a prática da conceituação adotada no campo médico.

O plantão ou pronto atendimento psicológico não dá ênfase à sintomatologia do sujeito, mas sim às suas potencialidades, sua experiência como um todo, levando em conta seus variados contextos. É importante ressaltar que esta modalidade de intervenção em um serviço-escola de Psicologia não comporta determinadas demandas, tais como emergências psiquiátricas (surtos psicóticos, no caso). Destina-se ao acolhimento das pessoas que a ele recorrem de maneira espontânea ou por encaminhamento de serviços parceiros, em busca de auxílio para questões de caráter emocional (GOMES, 2012).

No que se refere ao trabalho efetuado pelo plantonista, entende-se que este se vê frente a uma prática complexa, haja vista a necessidade de desenvolver uma disponibilidade para se defrontar com o inesperado e com a possibilidade de que o encontro com o paciente seja único (CHAVES; HENRIQUES, 2008). Como se configura como um atendimento frequentemente sem continuidade, o plantonista deve estar preparado para acolher variados tipos de demanda sem um planejamento prévio, dando um retorno imediato àquele que busca o plantão (SCORSOLINI-COMIN, 2014).

Mesmo com esta complexidade, nota-se um início e uma presença posterior deste tipo de intervenção nos serviços-escola de Psicologia (DOESCHER; HENRIQUES, 2012, GOMES, 2008; PAPARELLI; NOGUEIRA-MARTINS, 2007), espaços de formação de futuros psicólogos clínicos. Um exemplo disto trata da implantação do plantão psicológico realizada no serviço-escola de psicologia em uma universidade pública que será aqui apresentada.

Nesta Instituição de Ensino Superior, o plantão psicológico foi iniciado no ano de 2015, sendo denominado institucionalmente como Pronto Atendimento Psicológico. Tendo em vista a dificuldade de se fazer alterações na grade curricular, que demandam extensos trâmites institucionais, optou-se pela inserção deste serviço por meio de um projeto de extensão e não como disciplina obrigatória, como foi feito na USP.

Com isso, os acolhimentos acabavam sendo realizados por estudantes de últimos anos do curso de Psicologia, vinculados voluntariamente ao projeto, mas também poderiam ser realizados por psicólogos graduados vinculados à atividade. O plantão psicológico organizava-se como uma intervenção clínica oferecida diariamente, no período do almoço, além de ser oferecido ao longo de todo horário comercial da quarta-feira. Tendo em vista o caráter de plantão, não era necessário o agendamento prévio do atendimento, bastando que o interessado comparecesse no horário disponibilizado para esta atividade. 
Como se organizava como um projeto de extensão visava não só o oferecimento de um serviço psicológico para a comunidade, mas também se atentava em proporcionar ganhos no campo da formação do estudante, no sentido de aprimorar o raciocínio deste e seu manejo clínico. Neste caso, entende-se que se qualifica o estudante para uma diferente modalidade de atendimento clínico, fomentando o papel social desempenhado pelo psicólogo.

Nota-se que a prática de plantão psicológico no cenário nacional baseia-se mais amplamente na perspectiva humanista (SCORSOLINICOMIN, 2015; SOUZA; SOUZA, 2011), com propostas prioritariamente pautadas na Abordagem Centrada na Pessoa (SCORSOLINICOMIN, 2014) e Abordagem FenomenológicoExistencial (GONÇALVES; FARINHA, GOTO, 2016). Tendo em vista este cenário, almeja-se, por meio deste trabalho discutir como é o olhar psicanalítico a respeito dessa prática, pensando mais especificamente nas contribuições de uma escuta psicanalítica nos atendimentos realizados nos plantões.

Trata-se de um estudo teórico-clínico que visa articular a literatura referente ao plantão psicológico com os pressupostos teóricos da clínica psicanalítica, comilustração clínica sobre o atendimento em plantão psicológico realizado a partir desta perspectiva. No que se refere aos aspectos éticos, compreende-se que este trabalho respeita a Resolução n ${ }^{\circ}$ 510/2016 do Conselho Nacional de Saúde (BRASIL, 2016), que indica não ser necessária a tramitação por um Comitê de Ética em Pesquisa com Seres Humanos de trabalhos que proponham um "aprofundamento teórico de situações que emergem espontânea e contingencialmente na prática profissional". Nestes casos, entretanto, deve haver um cuidado quanto à apresentação dos dados de forma que estes não favoreçam a identificação dos sujeitos.

\section{Considerações Gerais Sobre a Clínica Psicanalítica}

Em 1896, Sigmund Freud criou o termo psicanálise para dar nome a um método particular de psicoterapia pautado na investigação dos processos mentais inconscientes (ROUDINESCO; PLON, 1998). Com a psicanálise, "Freud inventou um procedimento para que a verdade falasse: revelar os processos inconscientes que produzem os sintomas" (ROSA, 2004, p. 341).

Entende-se que a psicanálise como método de tratamento é produtora de efeitos terapêuticos (MARCOS; OLIVEIRA JÚNIOR, 2013). Todavia, a psicanálise não tem como objetivo uma cura, pelo menos não está aos moldes do tratamento clínicomédico até porque "Freud concebeu a análise como interminável” (MARCOS; OLIVEIRA JÚNIOR, 2013, p. 19). Pode-se falar que o processo analítico almeja sim uma cura apenas se esta for ao sentido trazido por Lacan (1998, p. 936), com a compreensão desta palavra não como designação propriamente de eliminação de um mal, mas em sintonia com a palavra francesa cure, vista como sinônimo de "tratamento, análise ou tratamento analítico."

Quanto ao processo analítico, entende-se que em psicanálise o "falar" corresponde a um "escutar". $\mathrm{O}$ analisando fala o que foi esquecido e o analista escuta de modo que o que falou também escute o que fala o que não sabe ou não quer saber. Nesta perspectiva, o escutar do analista pressupõe um ato e não uma simples percepção (CELES, 2005). O processo psicanalítico constitui-se, então, por meio da combinação entre as associações livres do analisando e a atenção flutuante do analista.

No que concerne à associação livre, é solicitado ao paciente que este comunique tudo o que lhe ocorre, sem deixar de revelar algo que the pareça insignificante, vergonhoso ou doloroso (CELES, 2005; MACEDO; FALCÃO,2005). Quantoà atenção flutuante, esta se relaciona com o desprendimento 
do analista de suas influências conscientes, de forma a deixar a atenção uniformemente suspensa e escutar o paciente sem o privilégio, a priori, de qualquer elemento de seu discurso (CELES, 2005; MACEDO; FALCÃO, 2005).

A associação livre e a atenção flutuante são processos concomitantes com o que se configura escuta psicanalítica. Esta escuta não tem função passiva, pois coloca em movimento o sujeito, fazendo-o falar, deparar-se com o seu não saber, com suas dúvidas sobre si e sobre o mundo (BASTOS, 2009). A escuta psicanalítica é ativa, provoca o analisando a se colocar diante de suas próprias palavras, leva-o a examinar e se dar conta de sua própria singularidade e se implicar com ela, isto é, dar consequências, decidir o que fazer com isso (BASTOS, 2009; ROSA, 2004).

O escutar demanda uma abstinência do analista, implicando-o a suportar aquela relação, à transferência, no caso. Aqui o analista deve "ocupar o lugar de suposto-saber sobre o sujeito uma estratégia para que o sujeito, supondo que fala para quem sabe sobre ele, fale e possa escutar-se e apropriar-se de seu discurso" (ROSA, 2004, p. 343). Ao escutar, o analista deve voltar o seu inconsciente em direção ao inconsciente do paciente, deve se atentar às palavras ditas e silenciadas, tendo em vista que há algo além do que foi dito para ser escutado.

Compreende-se que o inconsciente do paciente insiste para que seja escutado, funciona, assim, a partir de um mecanismo de repetição. A repetição é movida por componentes psíquicos recalcados que se atualizam num encontro analítico. $\mathrm{O}$ que se repete é algo que, por mais que se tente, não se pode recordar, é o impossível de se dizer (ALMEIDA; ATALLAH, 2008). Ao repetir, a pessoa em análise rodeia suas questões, sem conseguir efetivamente localizá-las, necessitando da ajuda do analista para apontar o caminho. Neste sentido, o trabalho em análise se desdobra a partir dos componentes contidos neste fenômeno, constatado a partir da fala do analisando (ALMEIDA; ATALLAH, 2008).
A psicanálise em seu sentido de um conjunto de métodos para que se analise o inconsciente tem, então, uma potencialidade além da clínica ortodoxa de divãs e settings extremamente específicos. Há um movimento possível de praticar a psicanálise em outros contextos e principalmente de fazer psicanálise em outros dispositivos, por meio do uso das ferramentas que ela oferta (BIRMAN, 1999; BUENO; PEREIRA, 2002; CASTANHO, 2009; MORETTO; TERZIS, 2010). O próprio Freud (1996, p. 181) em "Linhas de progresso na teoria psicanalítica" aponta a possibilidade de, em algum momento, o método psicanalítico necessitar ser readaptado, quando defende que "mais cedo ou mais tarde [...] defrontar-nos-emos, então, com a tarefa de adaptar a nossa técnica às novas condições."

Ao refletir sobre o plantão psicológico, entende-se que este é uma prática clínica da contemporaneidade, compreendendo que a psicanálise pode sim ser a teoria por detrás dessa prática (REBOUÇAS; DUTRA, 2010). Tanto o modelo de plantão quanto a análise tradicional embasada no referencial psicanalítico, exigem do plantonista ou do analista o mesmo comprometimento com a escuta e com o acolhimento. Ainda como semelhança entre estas práticas, ambas promovem, em suas devidas proporções, "um espaço de escuta a alguém que apresenta uma demanda psíquica [...] e oferece um momento no qual esse sujeito [...] possa ressignificar o seu estar no mundo" (REBOUÇAS; DUTRA, 2010, p. 19). Quando às diferenças entre o plantão psicológico e a análise, respaldadas na psicanálise, têm-se questões referentes às dimensões das demandas tratadas, durabilidade do "tratamento" e aprofundamento em relação às questões trazidas pelo sujeito.

Ao contrário de um tratamento analítico, o qual se configura como um processo demorado que almeja mudanças profundas e extensas, o plantão psicológico é uma prática na qual operam objetivos e tempo limitados. O serviço de plantão psicológico foge aos moldes tradicionais de setting psicanalítico quanto à frequência e continuidade, por conta da 
possibilidade do encontro com o paciente ser único. Em um plantão psicológico, no qual se atue a partir de uma perspectiva psicanalítica, faz-se necessário a adaptação da técnica à demanda trazida por quem procura este tipo de serviço. A questão fundamental delegada ao plantonista seria, então, estar atento àquilo que o paciente traz de mais urgente, focando os esforços ao longo do encontro, em auxiliá-lo a organizar tal aspecto.

\section{A Escuta Psicanalítica no Plantão Psicológico}

O encontro, no qual plantonista e sujeito em sofrimento psíquico deparam-se, não deixa de ser um encontro analítico, mesmo este sendo único e breve. Portanto, a escuta psicanalítica destaca-se como uma questão fundamental no atendimento em plantão psicológico. Assim como em um processo de análise, o plantonista também tem um espaço que lhe permite dotar da técnica da escuta psicanalítica, pressupondo que ele tenha uma atenção às manifestações do inconsciente, que se apresentam no decorrer da fala do sujeito (BASTOS, 2009).

A escuta do inesperado no plantão é também a escuta de um não-dito do discurso do sujeito (ROSA, 2004). Assim, naquele encontro, que possivelmente será único e breve, o plantonista vai mais além do que a investigação sintomatológica: quando começou e com que frequência isso ocorre. O plantonista tem, então, a possibilidade de tratar psicanaliticamente aquele sujeito que vem procurar atendimento no plantão psicológico, na medida em que, por meio da escuta psicanalítica, o terapeuta consegue escutar o inconsciente, escuta esta possibilitada pela transferência estabelecida ali naquele encontro, a fim de produzir um saber junto com o sujeito (ROSA, 2004).

Sobre esse saber que plantonista e sujeito produzem juntos, Freud já supunha que há no paciente um saber, que nem mesmo ele sabe que tem, mas que pode ser desperto, por meio da escuta do analista, atrelado à regra de associação livre
(BASTOS, 2009). Rosa (2004, p. 341) entende que "o saber está no sujeito, um saber que ele não sabe que tem e que se produz na relação", e que o plantonista pratica a "escuta do sofrimento e descobre que não deve eliminá-lo, mas criar uma nova posição diante do seu sentido" (ROSA, p. 341).

O cotidiano do plantão realizado no serviçoescola de Psicologia permitiu demonstrar este saber que está no sujeito e lhe é possibilitado realmente saber apenas durante o atendimento. $\mathrm{Na}$ prática clínica do plantão, várias vezes os sujeitos convocam o plantonista a ocuparem lugares de "conselheiros", na medida em que indagações com caráter afirmativo são feitas pelos sujeitos: "mas é isso que eu devo fazer, não é?". Vieira e Anjos (2013) encontraram em relatos de experiência de plantonistas da clínica escola da UFPA esta posição em que plantonistas sentiram-se colocados, a partir do momento em que se propuseram a escutar psicanaliticamente, em um só breve encontro, os sujeitos em sofrimento: posição de legitimação, como se realmente fossem sujeitos do saber, e não supostos saber.

A psicanálise, então, contribui nesse ponto a fim de amparar esse plantonista dando-lhe respaldo com a teoria do que seria o escutar psicanalítico no setting de plantão psicológico. Neste sentido, pode-se questionar: É uma escuta interventiva? Que dimensões têm essa intervenção? As contribuições de Rosa (2004), ao escrever sobre a pesquisa psicanalítica e sua fundamentação teórica, são de grande valia no entrelace entre os apontamentos da psicanálise e a prática do plantão psicológico. Entende-se que o método adotado no plantão é uma escuta ativa, como já dito, juntamente com uma interpretação do sujeito do desejo, que é pontuado quando se dota desta escuta ativa para a narrativa do usuário do plantão aquele que transparece no nãodito do sujeito, mas escutado pelo plantonista.

Quanto ao plantão psicológico pautado na psicanálise em comparação àquele empreendido pela Abordagem Centrada na Pessoa (ACP), 
considera-se que, assim como o que é proposto na escuta psicanalítica, um "fazer-se escutar" do saber do sujeito, a escuta centrada na pessoa entende que o sujeito tem uma "capacidade para crescer e se desenvolver na direção de suas potencialidades intrínsecas" (ZANONI, 2008, p. 16). Entende-se que, no atendimento, essas ditas potencialidades podem vir a serem "escutadas" pelo próprio sujeito. Além disso, a ACP também coloca o quanto o encontro entre plantonista e sujeito pode "tornar o cliente mais autônomo, para encontrar soluções para suas aflições psicológicas" (ZANONI, 2008, p. 16), o que está muito vinculado ao aspecto da abordagem psicanalítica que permite uma responsabilização do sujeito perante seu sofrimento, tornando-o, assim, consciente de seus processos.

De uma maneira geral, as duas escutas, psicanalítica ou humanista, em modalidade de atendimento em plantão, entendem que o encontro plantonista e sujeito pode ser potencializador. $\mathrm{Na}$ ACP tem-se que este encontro é "um processo de ajudar a pessoa em transição a experienciar e dar sentido ao que se experiencia, acreditando na sua própria capacidade de assumir novas situações de vida" (ZANONI, 2008, p. 21). E, na psicanálise, por meio da escuta clínica, tem-se o objetivo de fazer com que "os pacientes resgatem suas narrativas [...] tornando-se protagonistas de sua própria história" (MENDES; PARAVIDINI, 2007, p. 114), possibilitando a estes a inserção em um mundo desejante.

\section{Ilustrações Clínicas}

Como forma de ilustrar os conceitos teóricos acima discutidos, optou-se por apresentar uma ilustração clínica por meio de dois casos atendidos no plantão psicológico de um serviço-escola de psicologia sob uma perspectiva de demanda emergencial, por meio do referencial psicanalítico. Os atendimentos deram-se de forma única e foram realizados por uma psicóloga que atuava no referido serviço.
O primeiro caso clínico referiu-se a uma pessoa do sexo feminino, identificada como B, com aproximados 20 anos de idade. Procurou o plantão psicológico por demanda própria, com a queixa de ansiedade e pensamentos negativos relacionados à vida e morte.

Apontou para a presença desses pensamentos negativos, que a mesma identificava como "pessimistas" (sic), desde a pré-adolescência. Viajou para fora do país em um programa de intercâmbio, quando pensou "ter diminuido os pensamentos, ter visto a vida mais colorida" (sic). Contudo, logo após retornar ao país de origem, os pensamentos e sensações voltaram com maior intensidade. Relatou que, no momento, encontrava dificuldades em relacionamentos interpessoais. Indicou não sentir vontade de sair de casa, encontrar pessoas e ir para a faculdade. Estava em um relacionamento amoroso, mas sinalizava que não sabia "por que ainda estamos juntos, acho que não sinto mais nada por ele e, além disso, nós só brigamos" (sic).

Depois da descrição da queixa, B. falou sobre seu relacionamento familiar. Relatou que em sua família, as mulheres eram vistas como se estivessem abaixo dos homens. Devido a isto, sua mãe "obedecia $e$ admirava o marido" (sic), o que acabava por causar incômodo em B. Afirmou que "apesar de amar" (sic), tinha um complicado relacionamento com o pai, já que este havia se envolvido em problemas que comprometeram toda a família, e devido a isto não conseguia perdoá-lo. Contou que falava pouco com o pai e que brigavam muito, e que nessas brigas B. chegou a dizer para o pai que não o admirava mais e que ele só havia trazido problemas.

Logo após, B. disse para a plantonista que iria contar outra coisa, porém, achava que não era importante. A plantonista pontuou sua fala, apontando para a importância que tinha B. falar todos os pensamentos e sentimentos que lhe vinham à mente. De acordo com Macedo e Falcão (2005), isto é o que concerne à associação livre, permitindo que o sujeito coloque na fala tudo que ocorre consigo até mesmo o que lhe parece insignificante. 
Foi então que B. relatou comportamentos autolesivos, que implicam em atos de arranhar as pernas e usar objetos cortantes para feri-las. A plantonista questionou em quais momentos isso acontecia e B. expôs que se autolesionava todas as vezes em que "sentia raiva e angústia" (sic), descrevendo algumas situações nas quais havia se ferido até provocar machucados. À medida que B. recordava de certas situações, afirmou que "agora falando me parece que a dor provocada por mim mesma dói menos do que o que eu sinto" (sic). A escuta de si e a apropriação das próprias palavras, tornam-se instrumento hábil no desbravamento dos territórios mais desconhecidos, uma vez que o saber encontra-se no próprio sujeito, cabendo a quem oferece a escuta, conduzir tal descoberta (MACEDO; FALCÃO, 2005).

B. falou que decidiu procurar pelo plantão porque havia ficado mal dois dias antes devido ao fato de ter ficado sabendo que uma pessoa, foco de sua admiração, havia se suicidado. A partir de então, os pensamentos negativos "dominaram, $e$ parece que a vida não fazia mais sentido" (sic). A plantonista solicitou a B. que falasse mais sobre essa "admiração" e ela indicou que sentia dificuldades em admirar as pessoas e se recordou de quando era criança e tinha esse sentimento pelo pai, algo considerado impossível naquele momento. A plantonista, então, colocou que o que estava sentindo poderia estar relacionado a seu pai, pois provavelmente este seria a primeira pessoa que B. admirara e a angústia relacionada à falta de sentido na vida na verdade poderia estar ligada à fantasia do que sentiria se fosse o pai quem tivesse falecido. Este movimento de construção de um saber do sujeito juntamente com o plantonista é possível mediante a transferência. Mesmo que o plantão se caracterize por um único encontro, estudos como o de Rosa (2004) já entenderam que para o estabelecimento da transferência não são necessárias várias sessões. Outros estudos (QUINET, 2009; VICTRIO; SEI; BEZERRA, 2016) também citam a transferência prévia, por exemplo, no qual, antes mesmo do encontro e no início dele, já haveria um estado de projeção à figura do analista. Este conceito de transferência prévia e a não necessidade de várias sessões para o estabelecimento de uma transferência faz com que o dispositivo do plantão psicológico seja possível e eficaz, na medida em que a escuta ativa e transferência presentes dão "subsídio para o sujeito se impor no mundo do desejo" (ORTOLAN; SEI, 2016, p. 39).

B. relatou que fazia terapia há mais de um ano, contudo, disse sentir-se desconfortável com a terapeuta sem, contudo, conseguir interromper a terapia. Alegou não conseguir dizer à terapeuta que não queria mais continuar o trabalho. A plantonista questionou o que sentia e pediu para que B. falasse mais sobre isso. B. descreveu a situação como angustiante e disse sentir um misto de raiva e necessidade em relação à terapeuta. Toda semana pensava em desmarcar as sessões, entretanto, eram poucos os dias em que conseguia ligar para desmarcar e quando saia da sessão tinha sentimentos de raiva. Porém, na semana seguinte, mesmo com raiva sentia necessidade em ir à sessão. Conforme Palhares (2008), a própria figura do analista, no campo psíquico do paciente, incita ao mesmo tempo tanto a transferência quanto a resistência e estas oposições acabam por determinar a dinâmica analítica. A plantonista apontou os sentimentos de raiva e necessidade presentes na relação, que estes poderiam se assemelhar em sua relação com o pai. B. associou "verdade, é o que sinto pelo meu pai, mistura de raiva ao mesmo tempo em que preciso dele" (sic).

No que cabe ao plantão, a plantonista pontuou a necessidade de cessar com os comportamentos repetitivos autolesivos, afirmando que B. precisava redirecionar e ressignificar os sentimentos de raiva $\mathrm{e}$ angústia, que de certa forma eram responsáveis por isso. Foi indicado que B. avaliasse melhor a relação com a terapeuta. A reavaliação deveria se dar no sentido de percepção se realmente não existia uma identificação positiva com a terapeuta, ou, se estava ocorrendo uma identificação com o pai. E, se fosse neste sentido, B. deveria colocar estas questões 
para a terapeuta e trabalhá-las na própria terapia. Dessa forma, foi orientado que B. continuasse seu processo terapêutico com sua terapeuta, ou, então que procurasse por outra terapeuta, haja vista este ser imprescindível para tratar suas questões referentes ao relacionamento com o pai, assim como o pensamento e sentimentos negativos imbricados a suas relações familiares.

O segundo caso referiu-se a uma pessoa do sexo feminino, identificada como A., com aproximados 25 anos de idade. Foi encaminhada para atendimento psicológico por um serviço de saúde do município, o qual a mesma havia procurado com a queixa de ansiedade extrema, taquicardia e sensação de morte eminente. A. relatou ser a segunda vez em que havia procurado um serviço de saúde com as mesmas queixas. A partir de então foi diagnosticada com depressão e começou a fazer o uso de medicação. Além das queixas supracitadas, A. contou ter procurado o plantão psicológico por encontrar dificuldades para estudar, aprender e manter o foco principalmente nos afazeres acadêmicos.

Relatou que, antes de procurar ajuda além das crises de ansiedade tinha também dificuldades em sair de casa, pois, pensava que algo de ruim poderia acontecer tais como um assalto ou um acidente, pensamentos que lhe levaram à sensação iminente de morte, identificada como "tinha medo de morrer" (sic). Ao saber do serviço de plantão psicológico, A. resolveu procurar pelo serviço, porém com dúvidas de sua eficácia justamente por este ser pautado em um atendimento único e breve. Tendo em vista que o dispositivo de atendimento em forma de plantão, na perspectiva da psicanálise, assim como a análise propriamente dita, se caracteriza, primeiramente, como a escuta do inconsciente (ROSA, 2004), esta é possível de ocorrer em um único encontro também. Entende-se que a oferta do espaço de escuta para o sofrimento do sujeito, mesmo que seja apenas em um único encontro, pode promover um reposicionamento do sujeito diante sua queixa, fazendo-o produzir um saber que lhe seja próprio (LERNER et al., 2014).
Na medida em que este atendimento transcorreu, A. falou sobre sua família e frisou que era muito próxima da mãe. Contou que familiares próximos "sofriam de depressão e problemas emocionais gravíssimos" (sic). A. colocou que devido a isto, pensava que suas crises de ansiedade e depressão eram uma espécie de herança genética. A partir de então, começou a falar a respeito do relacionamento com o pai. Relatou que a mãe havia desenvolvido depressão por causa das traições que sofria por parte de seu marido e ver sua mãe sempre melancólica a deixava mal. Recordou que quando ainda criança, o pai levava os filhos na casa de amantes como álibi para os questionamentos da esposa.

A plantonista questionou se em algum momento A. havia contado para a mãe. A. relatou que não contava para a mãe com receio de magoá-la. A. disse que as brigas em casa eram constantes e que a mãe sempre soube sobre as traições, contudo, dizia que não poderia pedir o divórcio em função dos filhos, pois não tinha condições de sustentá-los sozinha.

A. descreveu sua relação com a mãe como "ligação especial" (sic) e chegou a relatar que nem mesmo tinha interesse em relacionamentos amorosos, pois namorar alguém implicaria em ficar menos tempo com a mãe. A plantonista apontou que a fala da mãe parecia suscitar-lhe algo, pois, dizia de uma situação na qual havia abdicado de seu bemestar em função dos filhos e, por isso, A. parecia também abdicar de algo por ela. A. falou que nunca havia pensado nisso e que parecia "fazer sentido, me sinto dessa forma, se saio de casa parece que estou abandonando ela" (sic). A interpretação da plantonista e a fala da paciente configuram a escuta psicanalítica, o que conforme Bastos (2009) é resultado da associação livre e atenção flutuante, que, por meio da fala, coloca o sujeito em movimento acerca do não saber a respeito de si e do mundo.

A. voltou a dizer sobre a faculdade e disse estar pensando em desistir da graduação. Tinha a possibilidade de ampliar o prazo, contudo estava em dúvida, havia parado e retornado para o curso, 
sendo aquele seu último prazo caso não houvesse ampliação. A plantonista colocou que dessa forma ela ficaria mais em casa e, consequentemente, na presença da mãe. Foi então que A. disse "cheguei a pensar que não teria problema se reprovasse, assim tenho mais tempo com a minha mãe, acho que não queria escutar meus próprios pensamentos" (sic). De acordo com Celes (2005), ao falar não é só o analista que escuta, mas o próprio sujeito que fala e escuta ao mesmo tempo, o que não sabe ou até mesmo o que não quer saber.

Quanto aos apontamentos realizados por meio do plantão psicológico, foi posto que as dificuldades de aprendizagem e foco não estavam atreladas a algum problema cognitivo, mas sim a uma necessidade emocional. Em vista disso, era importante que A. entendesse que tinha parte nesse processo. No que tange à abordagem psicanalítica, a responsabilização do sujeito pelo seu sofrimento o torna consciente e consequentemente mais autônomo. A. se posicionou em buscar estender o prazo da graduação e concluíla. De acordo com Bastos (2009), a escuta do analista faz desabrochar um saber que já existe no sujeito, saber este que proporciona a abertura para ressignificações de experiências (ROSA, 2004). Isto é percebido na modalidade de plantão psicológico também, na medida em que é neste encontro do plantonista com o analista que se faz possível a clarificação de uma demanda e as possibilidades de ação e ressignificação do sujeito frente ao seu sofrimento (CAMPOS; DALTRO, 2015; COINCARVALHO; OSTRONOFF, 2014).

Diante os apontamentos realizados no plantão psicológico, compete aqui enfatizar que sua prática com base no referencial psicanalítico constituise em uma escuta ativa, à medida que busca o sujeito de desejo, muitas vezes desconhecido ou ocultado pelo mesmo. $\mathrm{O}$ acolhimento do sofrimento se dá mediante essa escuta ativa, que acaba por amenizar o sofrimento do sujeito, com o intuito de abrir caminho para um novo sentido. Não se pode esquecer que, não importa o modelo de referencial psicanalítico, seja este o plantão ou a análise, ambos oferecem a escuta e a possibilidade de ressignificação (REBOUÇAS; DUTRA, 2010).

A plantonista pontuou, no caso de A., a necessidade de haver uma reestruturação da relação com a mãe de forma saudável. Colocações sobre dar continuidade na graduação e certa independência seriam produtivas para a saúde psíquica da paciente, assim como, desatrelar sua independência com o abandono da mãe também se apresentaram de suma importância. Contudo, entende-se que estas eram questões que necessitavam de um processo terapêutico, que ultrapassavam a abrangência de um único encontro proporcionado pelo plantão psicológico. Dessa forma, foi discutida a importância da inserção da mesma em terapia.

O processo de análise favorece a exteriorização das instâncias mais internas do analisando. Nesse sentido, a análise provoca a perda essencial do sujeito, o que mais tarde proporcionará uma reorganização psíquica. Em vista disso, ao invés de ter a finalidade de cura, a psicanálise promove o encontro do sujeito com o estranho que há nele mesmo. E é neste estranho, no Isso, de acordo com Freud, que se descortina o "eu". Agora sim a psicanálise tem um efeito curativo, na medida em que ir ao encontro de seu estranho, provoca a diminuição do sintoma (NASIO, 1993).

\section{Considerações Finais}

Entende-se, a partir do exposto, ser possível atuar com base no referencial psicanalítico em outros contextos que não uma clínica ortodoxa de divãs e settings específicos. Tal possibilidade pode ser constatada a partir da prática do plantão psicológico, na qual o plantonista, assim como em uma análise, possui um espaço que lhe permite utilizar uma importante ferramenta psicanalítica, a escuta.

Acredita-se, assim, que, em um serviço de plantão psicológico embasado em uma vertente 
psicanalítica, o plantonista se depara com a escuta do inesperado, com a escuta do inconsciente que, no centro da repetição, insiste para que seja escutado. Espera-se que, ao mesmo tempo em que é escutado pelo plantonista, o próprio indivíduo que fala se escute e que esta escuta possa de alguma forma, contribuir para que o sujeito se reposicione ou ressignifique o motivo que o fez procurar o plantão psicológico.

Adespeito do potencial de ajuda e de promoção de saúde mental deste tipo de intervenção psicológica, por ofertar um cuidado no exato momento de sua necessidade ou muito próximo desta, entendese que o plantão psicológico também possui seus limites. Como posto, há situações que demandam uma abordagem contínua, um processo terapêutico mais extenso, cabendo à dupla plantonista e pessoa atendida esclarecerem a demanda, a partir do referido processo de escuta, refletindo sobre os encaminhamentos mais pertinentes para cada situação.

\section{Referências}

ALMEIDA, L. P.; ATALLAH, R. M. F. O conceito de repetição e sua importância para a teoria psicanalítica. Ágora, Rio de Janeiro, v. 11, n. 2, p. 203-218, 2008. Disponível em: <http://www. scielo.br/scielo.php?script $=$ sci arttext\&pid $=$ S 1516 14982008000200003\&lng=en\&nrm=isohttp://dx.doi. org/10.1590/S1516-14982008000200003>. Acesso em: 11 dez. 2017.

BASTOS, A. B. B. I. A escuta psicanalítica e a educação. Psicólogo Informação, São Paulo, v. 13, n. 13, p. 91-98, 2009. Disponível em: <http://pepsic. bvsalud.org/scielo.php?script $=$ sci_arttext\&pid $=\mathrm{S} 1415$ $88092009000100006 \& \operatorname{lng}=\mathrm{es} \& n \mathrm{~nm}=\mathrm{iso}>$. Acesso em: 11 dez. 2017.

BIRMAN, J. Os sentidos da saúde. Physis: Revista de Saúde Coletiva, Rio de Janeiro, v. 9, n. 1, p. 7-12, 1999. Disponível em: <http://www.scielo.br/pdf/physis/ v9n1/01.pdf. 2017http://dx.doi.org/10.1590/S0103$73311999000100001>$. Acesso em: $11 \mathrm{dez} .2017$.

BRASIL. Ministério da Saúde. Conselho Nacional de Saúde. Resolução n ${ }^{\circ} 510$, de 7 de abril de 2016. Diário Oficial [da] República Federativa do Brasil, Brasília, 24 maio 2016. Seção 1, p. 44-46. Disponível em: <http:// conselho.saude.gov.br/resolucoes/2016/Reso510.pdf $>$. Acesso em: 11 dez 2017.

BRESCHIGLIARI, J. O.; JAFELICE, G. T. Plantão psicológico: ficções e reflexões. Psicologia: Ciência e Profissão, Brasília, v. 35, n. 1, p. 225-237, 2015. Disponível em: $\quad<$ http://www.scielo.br/scielo.php?script=sci arttext\&pid=S1414-98932015000100225\&lng=en\&nrm =iso http://dx.doi.org/10.1590/1982-3703000112014>. Acesso em: 11 dez. 2017.

BUENO, D. S.; PEREIRA, M. E. C. Sobre a situação analítica: a experiência da psicoterapia psicanalítica no Hospital Universitário da Unicamp. Pulsional: Revista de Psicanálise, Perdizes, v. 15, n. 157, p. 15-24, 2002. Disponível em: <http://www.editoraescuta.com.br/ pulsional/157_02.pdf>. Acesso em: $11 \mathrm{dez} .2017$.

CAMPOS, A. F.; DALTRO, M. A clínica ampliada no enfoque da gestalt-terapia: um relato de experiência em supervisão de estágio. Revista Psicologia, Diversidade e Saúde, Salvador, v. 4, n. 1, p. 59-68, 2015. Disponível em: $<$ https://www5.bahiana.edu.br/index.php/psicologia/ article/view/743http://dx.doi.org/10.17267/23173394rpds.v4i1.743>. Acesso em: 14 dez. 2017.

CASTANHO, P. C. G. A Instituição dentro de nós e as práticas institucionais em psicanálise. In: CONGRESSO LATINO AMERICANO DA FLAPAG, 18., 2009, Campinas. Anais ... Campinas: FLAPAG, 2009. p. 26-31.

CELES, L. A. Psicanálise é trabalho de fazer falar, e fazer ouvir. Psychê: Revista de Psicanálise, São Paulo, v. 9, n. 16, p. 25-48, dez. 2005. Disponível em: <http://pepsic. bvsalud.org/scielo.php?script $=$ sci_arttext\&pid=S1415$11382005000200003 \& \operatorname{lng}=\mathrm{pt} \& \mathrm{nrm}=\mathrm{iso}>$. Acesso em: 11 dez. 2017.

CHAVES, P. B.; HENRIQUES, W. M. Plantão psicológico: de frente com o inesperado. Psicologia Argumento, Curitiba, v. 26, n. 53, p. 151-157, 2008. Disponível em: <https://periodicos.pucpr.br/index. php/psicologiaargumento/article/view/19831/19133>. Acesso em: 11 dez. 2017.

COIN-CARVALHO, J. E.; OSTRONOFF, V. H. Cuidado e transformação social: avaliação da implantação do plantão comunitário no Complexo da Funerária. Estudos de Psicologia, Campinas, v. 19, n. 2, p. 89-156, 2014. Disponível em: <http://www. scielo.br/scielo.php?script $=$ sci_arttext\&pid $=$ S1413294X2014000200006http://dx.doi.org/10.1590/S1413294X2014000200006>. Acesso em: 14 dez. 2017.

DOESCHER, A. M. L.; HENRIQUES, W. M. Plantão psicológico: um encontro com o outro na urgência. Psicologia em Estudo, Maringá, v. 17, n. 4, p. 717-723, 2012. Disponível em: <http://www. 
scielo.br/scielo.php?script $=$ sci_arttext\&pid $=\mathrm{S} 1413$ 73722012000400018\&lng=en\&nrm=iso http://dx.doi. org/10.1590/S1413-73722012000400018>. Acesso em: 11 dez. 2017.

FREUD, S. Linhas de progresso na terapia psicanalítica. In: FREUD, S. Obras psicológicas completas de Sigmund Freud. Rio de Janeiro: Imago, 1996. p. 169-181. (Edição Standard Brasileira das Obras Psicológicas Completas de Sigmund Freud, v. 17).

FUJISAKA, A. P. et al. Plantão psicológico em centroescola: tradição, reinvenção e rupturas. In TASSINARI, M. A.; CORDEIRO, A. P. S.; DURANGE, W. T. (Org.). Revisitando o plantão psicológico centrado na pessoa. Curitiba: CRV, 2013. p. 61-82.

GOMES, F. M. D. Plantão psicológico: atendimentos em situações de crise. Vínculo, São Paulo, v. 9, n. 2, p. 18-26, 2012. Disponível em: <http://pepsic. bvsalud.org/scielo.php?script=sci_arttext\&pid=S1806$24902012000200004 \& \operatorname{lng}=p t \& n r m=i s o>$. Acesso em: 11 dez. 2017.

GOMES, F. M. D. Plantão psicológico: novas possibilidades em saúde mental. Revista da SPAGESP, Ribeirão Preto, v. 9, n. 1, p. 39-44, 2008. Disponível em: $\quad<$ http://pepsic.bvsalud.org/scielo.php?script=sci arttext\&pid=S1677-29702008000100007\&lng $=$ pt\&nrm =iso $>$. Acesso em: 11 dez. 2017.

GONÇALVES, L. O.; FARINHA, M. G.; GOTO, T. A. Plantão psicológico em unidade básica de saúde: atendimento em abordagem humanista-fenomenológica. Revista da Abordagem Gestáltica, Goiânia, v. 22, n. 2, p. 225-232, 2016. Disponível em: <http://pepsic. bvsalud.org/scielo.php?script=sci_arttext\&pid=S1809$68672016000200015 \& \operatorname{lng}=$ pt\&nrm $=$ iso $>$. Acesso em: $11 \mathrm{dez} .2017$.

LACAN, J. Escritos. Rio de Janeiro: J. Zahar, 1998.

LERNER, A. B. C. et al. Plantão Institucional: uma modalidade de intervenção face ao mal-estar contemporâneo na educação. Estilos da Clínica, São Paulo, v. 19, n. 1, p. 199-208, 2014. Disponível em: $\quad<$ https://www.revistas.usp.br/estic/article/ download/81010/84656>. Acesso em: 14 dez. 2017.

MACEDO, M. M. K.; FALCÃO, C. N. B. A escuta na psicanálise e a psicanálise da escuta. Psychê: Revista de Psicanálise, São Paulo, v. 9, n. 15, p. 6576, 2005. Disponível em: <http://pepsic.bvsalud. org/scielo.php? script $=$ sci_arttext\&pid $=$ S 1415 $11382005000100006 \& \operatorname{lng}=\mathrm{pt} \& \mathrm{n} r \mathrm{~m}=\mathrm{iso}>$. Acesso em: 11 dez. 2017.

MARCOS, C. M.; OLIVEIRA JÚNIOR, E. S. O sintoma entre a terapêutica e o incurável: uma leitura lacaniana.
Psicologia Clínica, Rio de Janeiro, v. 25, n. 2, p. 17-31, 2013.

MENDES, E. D.; PARAVIDINI, J. L. L. Os significantes da escuta psicanalítica na clínica contemporânea. Psychê: Revista de Psicanálise, São Paulo, v. 11, n. 20, p. 99-116, 2007. Disponível em: <http://pepsic. bvsalud.org/scielo.php?script=sci_arttext\&pid=S1415$11382007000100007 \& \operatorname{lng}=$ pt\&nrm $=$ iso $>$. Acesso em: 11 dez. 2017.

MORETTO, C. C.; TERZIS, A. O sofrimento nas instituições e possibilidades de intervenção grupal. Arquivos Brasileiros de Psicologia, Rio de Janeiro, v. 62, n. 3, p. 42-47, 2010. Disponível em: <http://pepsic. bvsalud.org/scielo.php?script=sci_arttext\&pid=S1809$52672010000300006 \& \operatorname{lng}=\mathrm{pt} \& \mathrm{nrm}=\mathrm{iso}>$. Acesso em: 11 dez. 2017.

NASIO, J-D. Cinco lições sobre a teoria de Jacques Lacan. Rio de Janeiro: J. Zahar, 1993.

ORTOLAN, M. L. M.; SEI, M. B. Tornar-se plantonista e psicanalista: a experiência de uma estudante de psicanálise no plantão psicológico da UEL. Revista da Extensão, Farroupilha, v. 12, p. 36-42, 2016. Disponível em: $\quad<$ https://www.academia.edu/26806833/Tornarse_plantonista_e_psicanalista_a_experi\% $\%$ C $\%$ AAncia de_uma_estudante_de_psican\%C3\%A1lise_no_ plant\% $\mathrm{C} 3 \% \mathrm{~A} 3 \mathrm{o} \_$psicol\%C3\%B3gico_da_UEL $>$. Acesso em: 14 dez. 2017.

PALHARES, M.C.A. Transferência e contratransferência: a clínica viva. Revista Brasileira de Psicanálise, São Paulo, v. 42, n. 1, p. 100-111, 2008. Disponível em: $<$ http://pepsic.bvsalud.org/scielo.php? script $=$ sci arttext\&pid=S0486-641X2008000100011\&lng=pt\&nrm =iso>. Acesso em: 11 dez. 2017.

PAPARELLI, R. B.; NOGUEIRA-MARTINS, M. C. F. Psicólogos em formação: vivências e demandas em plantão psicológico. Psicologia: Ciência e Profissão, Brasília, v. 27, n. 1, p. 64-79, 2007. Disponível em: $\quad<$ http://www.scielo.br/scielo.php?script=sci arttext\&pid=S1414-98932007000100006\&lng=en\&nrm =iso>. Acesso em: 11 dez. 2017.

QUINET, A. A função das entrevistas preliminares. In: . As 4+1 condições da análise. Rio de Janeiro: J. Zahar, 2009. p. 13-34.

REBOUÇAS, M. S. S.; DUTRA, E. Plantão psicológico: uma prática clínica da contemporaneidade. Revista da Abordagem Gestáltica, Goiânia, v. 16, n. 1, p. 1928, 2010. Disponível em: <http://pepsic.bvsalud. org/scielo.php? script $=$ sci_arttext\&pid=S1809$68672010000100004 \& \operatorname{lng}=\mathrm{pt \& n}{ }^{-} \mathrm{nm}=\mathrm{iso}>$. Acesso em: 11 dez. 2017. 
ROCHA, M. C. Plantão psicológico e triagem: aproximações e distanciamentos. Revista do NUFEN, São Paulo, v. 3, n. 1, p. 119-134, 2011. Disponível em: $\quad<$ http://pepsic.bvsalud.org/scielo.php?script=sci arttext\&pid=S2175-25912011000100007\&lng=pt\&nrm =iso>. Acesso em: $11 \mathrm{dez} .2017$.

ROSA, M. D. A pesquisa psicanalítica dos fenômenos sociais e políticos: metodologia e fundamentação teórica. Revista Mal Estar e Subjetividade, Fortaleza, v. 4, n. 2, p. 329-348, 2004. Disponível em: $<$ http://periodicos.unifor. $\mathrm{br} / \mathrm{rmes} /$ article/download/1509/3464>. Acesso em: 11 dez. 2017.

ROUDINESCO, E.; PLON, M. Dicionário de psicanálise. Rio de Janeiro: J. Zahar, 1998.

SCORSOLINI-COMIN, F. Atenção psicológica e umbanda: experiência de cuidado e acolhimento em saúde mental. Estudos e Pesquisas em Psicologia, Rio de Janeiro, v. 14, n. 3, p. 773-794, 2014. Disponível em: $<$ http://www.e-publicacoes.uerj.br/index.php/revispsi/ article/view/13882/10602>. Acesso em: 11 dez. 2017.

SCORSOLINI-COMIN, F. Plantão psicológico e o cuidado na urgência: panorama de pesquisas e intervenções. Psico-USF, Bragança Paulista, v. 20, n. 1, p. 163-173, 2015. Disponível em: <http://www.scielo. br/pdf/pusf/v20n1/1413-8271-pusf-20-01-00163.pdf>. Acesso em: 11 dez. 2017.
SOUZA, B. N.; SOUZA, A. M. Plantão psicológico no Brasil (1997-2009): saberes e práticas compartilhadas. Estudos de Psicologia, Campinas, v. 28, n. 2, p. 241249, 2011. Disponível em: <http://www.scielo.br/scielo. php?script $=$ sci_arttext\&pid $=$ S0103-166X201100020001 $1 \& \operatorname{lng}=$ en\&nrm=iso $>$. Acesso em: 11 dez. 2017.

VICTRIO, K, C.; SEI, M. B.; BEZERRA, P. V. A psicanálise no Pronto Atendimento: há transferência? In: JORNADA DE PRÁTICAS CLÍNICAS EM PSICOLOGIA: 40 anos de Clínica Psicológica da UEL, 1., 2016, Londrina. Anais... Londrina: UEL, 2016. p. 46-47. Disponível em: <http://www.uel.br/ clinicapsicologica/pages/arquivos/Anais\%20-\%20I\%20 Jornada $\% 20 \mathrm{de} \% 20$ Praticas $\% 20$ Clinicas $\% 20 \mathrm{em} \% 20$ Psicologia.pdf $>$. Acesso em: 14 dez. 2017.

VIEIRA, E. M.; ANJOS, K. P. L. Tornar-se plantonista: o fluxo das atitudes facilitadoras a partir da experiência de plantonistas iniciantes. In: TASSINARI, M. A.; CORDEIRO, A. P. S.; DURANGE, W. T. (Org.). Revisitando o plantão psicológico centrado na pessoa. Curitiba: CRV, 2013. p. 61-82.

ZANONI, M. R. L. Plantão psicológico em um serviço universitário de psicologia: a experiência de aprimorandas. 2008. 81 f. Dissertação (Mestrado em Psicologia) Pontifícia Universidade Católica de Campinas, Campinas. 